\title{
A DELIMITAÇÃO DOS CICLOS DE APRENDIZAGEM E A PERIODIZAÇÃO DO DESENVOLVIMENTO PSICOLÓGICO
}

Edival Sebastião Teixeira*

Resumo: O objetivo deste trabalho é contribuir para a discussão sobre a questão da organização da escolarização em ciclos de aprendizagem. No texto afirma-se que existem lacunas na pesquisa sobre essa modalidade de organização pedagógica, sobretudo em relação aos seus fundamentos psicológicos. Destaca-se o problema da delimitação dos limiares inferior e superior dos ciclos, e argumenta-se que é justamente nesse aspecto que se encontra a questão mais difícil para a pesquisa psicológica nessa área. $\mathrm{O}$ texto apresenta alguns aspectos da teoria vygotskiana sobre o desenvolvimento psicológico e, com base no conceito de situação social de desenvolvimento e na periodização elaborada por Vygotski, sugere uma periodização de ciclos de aprendizagem. Não obstante, o trabalho conclui afirmando que tal sugestão deve ser encarada tão somente como uma provocação, no sentido de suscitar o levantamento de temáticas para a pesquisa sobre fundamentos psicológicos para projetos pedagógicos de ciclos de aprendizagem.

Palavras-chave: ciclos de aprendizagem; desenvolvimento psicológico; Vygotski. 


\section{Introdução}

A produção científica sobre as experiências brasileiras de organização da escolarização em ciclos de aprendizagem já é bastante significativa (BARRETO \& SOUZA, 2004; JACOMINI, 2004; TEIXEIRA, 2005; MAINARDES, 2006). Não obstante, autores como Barreto e Souza (2004) e Mainardes (2006) apontam a existência de importantes lacunas nessa produção. Esses pesquisadores destacam a necessidade de estudos mais aprofundados sobre as políticas de implantação do sistema de ciclos, tanto nos seus aspectos macro-institucionais, materializados nos sistemas de ensino, quanto nos seus aspectos micro-institucionais, os quais repercutem nas unidades escolares, na formação de professores e nas salas de aula.

Existem, ainda, lacunas importantes em outras direções, principalmente quanto à pesquisa sobre os fundamentos psicológicos dos projetos pedagógicos de ciclos de aprendizagem. Nesse aspecto, destacamos o problema da própria periodização dos ciclos de aprendizagem, isto é, da delimitação de seus limiares inferior e superior.

Nesse sentido, analisando o problema das relações temporais entre aprendizagem e desenvolvimento na perspectiva vygotskiana, Teixeira (2005) faz alguns questionamentos sobre os critérios utilizados para as periodizações de ciclos de aprendizagem que tem sido feitas no Brasil. No entanto, esse autor deixa aberta essa questão, limitando-se a afirmar que ainda não existem garantias científicas que sustentem uma delimitação ótima para um ciclo de aprendizagem.

De fato, é justamente na delimitação dos limiares que se encontra a questão mais espinhosa para a psicologia educacional para a sustentação de projetos pedagógicos de ciclos de aprendizagem. Mas, por outro lado, entendemos que esse problema exige que os psicólogos considerem a necessidade e a importância da pesquisa acerca de critérios para a periodização dos ciclos de aprendizagem, tendo em vista que a implantação desses projetos pedagógicos tem sido encarada como uma alternativa bastante viável para a melhoria da qualidade da Educação no Brasil (VASCONCELLOS, 1999; PARO, 2001; FREITAS, 2003; JACOMINI, 2004; TEIXEIRA, 2005).

Este trabalho tem por objetivo contribuir para essa discussão, apresentando alguns aspectos da teoria vygotskiana sobre o 
desenvolvimento psicológico, os quais consideramos relevantes para a sustentação de projetos pedagógicos de ciclos de aprendizagem.

O texto está organizado em dois tópicos. No primeiro, apresentamos os critérios para a periodização do desenvolvimento psicológico da teoria histórico-cultural. No segundo tópico, com base no conceito de situação social de desenvolvimento e na periodização elaborada por Vygotski (1996), apresentamos uma sugestão para a periodização de ciclos de aprendizagem.

Não obstante, essa sugestão deve ser encarada tão somente como uma provocação no sentido de suscitar o levantamento de temáticas para a pesquisa sobre fundamentos psicológicos para projetos pedagógicos de ciclos de aprendizagem.

\section{Critérios para a periodização do desenvolvimento na teoria vygotskiana}

A morte prematura impediu que Vygotski tivesse tempo de elaborar um sistema completo de periodização do desenvolvimento psicológico. No entanto, esse autor lançou as bases de um sistema, e muitas de suas teses foram desenvolvidas por Leontiev e Elkonin (DAVIDOV, 1988; ELKONIN, 1996).

Davidov considera que esses autores adotam uma posição comum no seu enfoque sobre o problema do desenvolvimento. Em primeiro lugar, todos consideram que muitas das periodizações são inconsistentes porque se concentram em traços externos do desenvolvimento em detrimento da essência interna desse processo, que se manifesta por mudanças bruscas no percurso do desenvolvimento. Em segundo lugar, todos consideram que a periodização deve levar em conta as mudanças na atividade da criança, porque sua personalidade muda como um todo integral em sua estrutura interna durante o processo. Em terceiro lugar, os autores da escola vygotskiana concordam que o exame das fontes de desenvolvimento deve realçar a ligação de cada um dos períodos com um tipo principal de atividade que caracteriza o período dado. Finalmente, em quarto lugar, todos eles consideram que são as atividades integrais da criança, específicas para cada idade, que determinam, ao mesmo tempo, as transformações psíquicas, a consciência e suas relações com o meio. 
$\mathrm{Na}$ teoria vygotskiana, as idades correspondem a determinados períodos, mais ou menos prolongados, caracterizados pela existência de uma formação psicológica específica ou uma atividade dominante, conforme Leontiev (1998). Essa formação psicológica, por sua vez, define os limites e as possibilidades do sujeito em sua relação com o mundo, de acordo com cada período específico.

Vygotski (1996) agrupa todas as teorias que se ocupam do problema da periodização do desenvolvimento psicológico em duas concepções fundamentais: de um lado estão aquelas que caracterizam o desenvolvimento como se este fosse a realização de capacidades inatas, onde nada de novo surge, à exceção do próprio crescimento orgânico; de outro lado estão as teorias que tomam o desenvolvimento como um processo contínuo de automovimento, cuja característica essencial é a permanente aparição e formação do novo, daquilo que era inexistente em estágios anteriores.

Dentre as teorias que se guiam por essa segunda concepção, Vygotski diferencia, ainda, as idealistas e as materialistas. No primeiro caso, encontram-se teorias que tomam o desenvolvimento como um processo de evolução criadora, cuja força motriz, autônoma e interna, conduz a personalidade, pela vontade do sujeito, ao aperfeiçoamento. Por sua vez, as teorias materialistas consideram "o desenvolvimento como um processo que se distingue pela unidade do material e do psíquico, do social e do pessoal na medida em que a criança vai se desenvolvendo" (VYGOTSKI, 1996, p. 254). O que diferencia as teorias idealistas das materialistas é o fato de que essas últimas consideram todo o entorno da criança como um aspecto fundamental no processo do desenvolvimento. Quer dizer, consideram que o contexto, enquanto conjunto de condições objetivas, está relacionado com a criança de uma forma tal que vai muito além da idéia simples da existência de certos fatores ambientais que exercem pressão sobre o material genético.

Para Vygotski (1996), uma investigação criteriosa do desenvolvimento deve centrar-se nas neoformações, graças as quais se pode determinar o essencial em cada idade. Uma neoformação caracteriza-se por um novo tipo de estrutura da personalidade e da atividade, produzidas na interação social e que determina a consciência 
da criança, sua relação com o meio, bem como todo o curso de seu desenvolvimento. Isso significa que as neoformações, além de serem a estrutura (atual) da personalidade, atuam também como que guias desse processo. E é por essa razão que a compreensão de uma determinada idade exige que se analise, em sua totalidade, o processo de mudança da personalidade. Processo este marcado pela hegemonia de uma forma de atividade em cada idade específica.

Por conseguinte, de acordo com essa teoria, o único fundamento possível para uma periodização consistente do desenvolvimento psicológico tem de ser buscado nas mudanças internas do próprio processo. Uma tal periodização precisa considerar a dinâmica do desenvolvimento infantil e a dinâmica de passagem de uma idade a outra (TEIXEIRA, 2003). Nessa dinâmica, as transformações que ocorrem no processo de desenvolvimento podem se desencadear de maneira lenta e gradual ou de maneira crítica e vigorosa. No primeiro caso, decorrem as idades estáveis; no segundo, os períodos críticos.

Nas idades estáveis, tudo se processa de uma forma em que as mudanças na personalidade vão ocorrendo de maneira quase imperceptível. Assim, durante um certo período de tempo não são produzidas mudanças bruscas capazes de reestruturar a personalidade inteira da criança. Isso ocorre porque as transformações que se originam nessas idades vão ocorrendo de modo cumulativo e somente se tornam visíveis após um lapso relativamente longo. Mas, quando o fazem, emergem como uma formação qualitativamente nova, evidenciando que enormes e importantes transformações na personalidade da criança são operadas durante o processo de desenvolvimento.

No esquema geral da periodização vygotskiana as idades estáveis compreendem tempos mais prolongados que as idades críticas. São elas: a) primeiro ano (entre o $2^{\circ}$ e o $12^{\circ}$ mês de vida); b) primeira infância (entre 1 e 3 anos); c) idade pré-escolar (entre 3 e 6 anos); idade escolar (entre 8 e 12 anos); adolescência (entre 14 e 18 anos). Portanto, pelos critérios cronológicos quase a totalidade do tempo destinado à Educação Básica, no Brasil, corresponde a períodos estáveis.

As passagens de uma idade a outra são marcadas por crises mais ou menos violentas. Vygotski (1996) denomina esses períodos como: 
a) crise pós-natal, "período de transição e de conexão entre os últimos meses do desenvolvimento intra-uterino e as primeiras semanas após o nascimento" (OLIVEIRA \& TEIXEIRA, 2002, p. 36); b) crise do primeiro ano; c) crise dos três anos; d) crise dos sete anos; e) crise dos 13 anos.

Os períodos de crise compreendem lapsos de tempo relativamente curtos, nos quais ocorrem mudanças bruscas e rupturas no psiquismo da criança, de modo que sua personalidade muda por completo. Todavia, as crises surgem de forma quase imperceptível, fato este que dificulta a determinação de seu início e de seu fim em relação às idades contíguas. Além disso, tais períodos apresentam um momento de agudização das crises, sendo que são esses aspectos que os diferenciam sensivelmente das idades estáveis.

Nesses períodos agudos, muitas crianças podem ficar excessivamente reativas à educação escolar, causando queda no rendimento, no interesse pelas aulas, bem como uma diminuição geral de sua capacidade de trabalho. Muitas crianças podem, ainda, entrar em conflitos mais ou menos agudos com as pessoas de seu entorno, bem como "sofrer dolorosas vivências e conflitos íntimos" (VYGOTSKI, 1996, p. 256). Finalmente, essas idades se caracterizam também pelo fato de que as crianças, quando as vivenciam, parecem perder a índole impetuosa com que se entregavam às atividades que lhes despertavam maior interesse.

Os elementos determinantes das crises não se encontram em hipotéticas disposições internas da criança, mas nas condições concretas do seu contexto relacional. Então, dado que são encontradas múltiplas possibilidades de conformações contextuais, explica-se o fato de que ocorrem distintas manifestações das idades críticas em diferentes crianças. Mas, por outro lado, o processo de desenvolvimento não consiste numa bem orientada sucessão de eventos, cuja manifestação esteja condicionada ao ambiente. Por essa razão, não é a presença ou a ausência de determinadas condições externas que desencadeiam as crises, porque o surgimento desses períodos é intrínseco à própria lógica interna do processo de desenvolvimento.

$\mathrm{O}$ final de cada período crítico representa o ápice do processo de viragem de uma idade à outra. Dessa forma, pode-se afirmar que todo 
o processo de desenvolvimento contém em si processos de criação, de redução e de extinção.

Com efeito, tendo em vista que todo o processo de desenvolvimento obedece as leis da dialética, esses períodos críticos são essencialmente positivos. Ainda que soe contraditório, esses momentos de crise são momentos de criação, porque em qualquer processo de desenvolvimento o anterior e o atual têm de desaparecer para dar lugar ao novo.

Por conseguinte, todo o aparente trabalho destrutivo que se realiza nos períodos críticos não é mais do que uma parte de um processo de crescimento. De outra forma, as idades críticas são indispensáveis para o surgimento do novo na personalidade. Por isso, Vygotski (1996, p. 259) é muito explícito quando afirma que "o conteúdo negativo do desenvolvimento nos períodos críticos é tão somente a faceta inversa ou velada das mudanças positivas da personalidade que configuram o sentido principal e básico de toda idade crítica".

Nos períodos críticos, assim como nas idades estáveis, surgem formações novas na personalidade. Todavia, as formações novas desses períodos são transitórias e não se conservam na personalidade da mesma forma como surgem e se manifestam, contrariamente ao que acontece com as formações novas das idades estáveis. As formações novas das etapas críticas são assumidas pelas formações das idades estáveis seguintes, incluindo-se nelas como instâncias subordinadas, sem existência própria e de tal modo transformadas e dependentes que desaparecem como tais, embora continuem participando do desenvolvimento em estado latente.

Ao discutir o problema da estrutura e a dinâmica das idades, Vygotski destaca que sua tese geral consiste em que o processo de desenvolvimento, em cada idade, constitui um todo único, uma formação global como uma estrutura determinada, apesar da complexidade de sua organização e composição e da multiplicidade de processos parciais que o integram. A estrutura da idade - ou da personalidade - é essa formação global que, por si mesma, determina o destino e o significado de cada uma de suas partes constituintes; que atuam, por sua vez, de modo coordenado. Por isso, em cada período do desenvolvimento as mudanças na estrutura interna da personalidade ocorrem como um todo "e as leis que regulam esse todo determinam a dinâmica de cada 
uma de suas partes" (VYGOTSKI, 1996, p. 262). Isso significa que essas estruturas específicas para cada idade - as neoformações - são como elementos que guiam o desenvolvimento. Essas estruturas, por serem específicas, nunca se repetem durante todo o tempo do desenvolvimento psicológico.

Vygotski distingue entre linhas centrais e/ou principais de desenvolvimento e linhas acessórias de desenvolvimento. As linhas principais dizem respeito aos processos mais imediatamente relacionados com a neoformação principal de determinada idade; as linhas acessórias são os processos e mudanças parciais que ocorrem nessa mesma idade. Na dinâmica do processo de desenvolvimento, as linhas principais numa idade se convertem em linhas acessórias noutra, uma vez que o significado e o peso específico de cada uma dessas linhas se modificam na nova estrutura.

Por exemplo, no primeiro ano de vida, a nova formação básica caracteriza-se pelo incremento gradual dos recursos energéticos da criança, sobretudo do sistema nervoso como premissa indispensável para todas as linhas de desenvolvimento superiores e a mudança na dinâmica da relação do bebê com o mundo. Assim, embora a criança use alguma forma para comunicar suas necessidades, no primeiro ano a mesma ainda está privada do seu meio mais essencial: a linguagem humana. Por essa razão, a comunicação pré-lingüística é visual e ativa. No entanto, mais que uma comunicação baseada no entendimento mútuo, "trata-se de manifestações emocionais, de transferência de afetos, de reações positivas ou negativas ante a mudança do momento principal de qualquer situação em que se encontra o bebê - o aparecimento de outra pessoa" (VYGOTSKI, 1996, p. 304). Quer dizer, ainda que a criança obtenha aquisições importantes na comunicação no primeiro ano de vida e a linguagem se constitua como um dos mais importantes elementos de mediação, esta é acessória em relação aos ganhos de natureza biológica; porque, nessa etapa da vida, a linguagem está muito mais ligada a necessidades de natureza vital ou afetiva.

Mas, na medida em que o desenvolvimento progride, na primeira infância a linguagem adquire o status de principal meio de comunicação e de compreensão da linguagem dos outros. Assim, pois, nessa etapa, a linguagem liga-se firmemente com o processo de gênese da 
consciência, representando a linha central sobre a qual se assenta o desenvolvimento infantil e sob cuja interferência se transformam, essencialmente, as relações entre a criança e seu meio na primeira infância. Por conseguinte, a linguagem se torna a linha principal do desenvolvimento e a que leva a mais importante nova formação dessa etapa: a consciência. E, assim, sucessivamente vão se modificando as linhas de desenvolvimento: o que é o acessório numa etapa, noutra pode vir a ser o principal.

Para Vygotski, uma compreensão plena do desenvolvimento psicológico exige, ainda, que se leve em conta a dinâmica do processo de transformação das formações globais que são as estruturas das idades. É preciso compreender o mecanismo através do qual as neoformações aparecem, se consolidam-se e novamente se transformam. E para se compreender esse processo, a condição essencial e primeira é considerar que as relações que se estabelecem entre a criança e seu entorno, sobretudo o social, são dinâmicas, específicas e únicas para cada idade. Então, os modos de relação entre uma determinada criança da idade escolar e seu contexto não se repetirão quando essa mesma criança estiver na adolescência, por exemplo.

E assim, na análise que faz da dinâmica da idade, Vygotski introduz o conceito de situação social do desenvolvimento, que, em rigor, significa o contexto no qual a criança se insere - e o modo como se insere - em cada idade específica. O autor considera a situação social do desenvolvimento como ponto de partida para todas as transformações dinâmicas que se produzem no desenvolvimento durante o período de cada idade. Com efeito, é nesse contexto relacional que se determinam as propriedades da personalidade, tendo em vista que a realidade social é a verdadeira fonte e condutora do desenvolvimento (VYGOTSKI, 1995, 1996)

Para Davidov (1988), o conceito de situação social do desenvolvimento tem relação direta e constitui o ponto de partida para o conceito de atividade dominante, desenvolvido por Leontiev. Esse autor considera esses dois conceitos, o de Vygotski e o de Leontiev, como sinônimos.

De fato, Leontiev, partindo das concepções vygotskianas, desenvolveu a idéia de que em cada etapa do desenvolvimento existe 
uma atividade principal que domina todo o processo de constituição do psiquismo. Mas a atividade principal (atividade dominante), adverte Leontiev, não deve ser simplesmente compreendida como aquela que é mais observada do ponto de vista quantitativo ou como aquela a qual a criança dedica mais tempo. Da mesma forma, não se trata de que a atividade dominante exclua outras possibilidades. Por exemplo, na primeira infância a atividade dominante é o jogo, a brincadeira, mas isso não significa que outros tipos de atividade sejam totalmente ausentes nesse período.

A atividade dominante é aquela "cujo desenvolvimento governa as mudanças mais importantes nos processos psíquicos e nos traços psicológicos da personalidade da criança, em um certo estágio de seu desenvolvimento" (LEONTIEV, 1998, p. 65). Em outras palavras, a atividade dominante é o critério que marca o (principal) modo como a criança se relaciona com sua realidade num determinado estágio, decorrendo daí sua enorme importância para a constituição do psiquismo.

O que caracteriza uma idade, como vimos, é a atividade dominante. Mas, cada idade tem também um conteúdo específico dado na cultura. Então, considerando que o desenvolvimento ocorre porque o sujeito se apropria das formas de cultura socialmente elaboradas e que essas formas são mutáveis, então devemos concordar que o conteúdo de cada estágio do desenvolvimento é também mutável, embora esses estágios obedeçam a uma seqüência precisa. Quer dizer, apesar do caráter periódico do desenvolvimento, o conteúdo dos estágios é dependente das condições concretas nas quais ocorre o desenvolvimento. O que determina o conteúdo de cada estágio não é propriamente a faixa-etária em que a criança se encontra, porque os "próprios limites de idade de um estágio, pelo contrário, dependem de seu conteúdo e se alteram pari passu com a mudança nas condições histórico-sociais" (LEONTIEV, 1998, p. 66).

E assim, se aceitarmos os critérios apresentados como válidos para a periodização e para a delimitação temporal de cada idade, e que esses limites dependem das formas de atividade social encarnada nas formas da cultura, então teremos de admitir a impossibilidade de uma periodização válida para todos os tempos e lugares. Disso resultará 
termos de admitir que qualquer periodização só pode fazer sentido num determinado contexto, ainda que amplo como, por exemplo, a sociedade ocidental escolarizada do início do século XXI.

De todo modo, o fato é que as pessoas vão avançando em seu desenvolvimento ao longo da vida. As idades vão sendo superadas, as atividades dominantes vão se substituindo, enfim, o domínio da realidade objetiva vai se efetivando sob outras bases na medida em que o sujeito cresce e experimenta o mundo. Portanto, ainda que o conteúdo de uma idade dependa da realidade material objetiva, há que se considerar a existência de algum mecanismo que provoca e desencadeia a mudança da atividade dominante.

Esse mecanismo começa a evidenciar-se a partir do momento em que a criança começa a se dar conta de que o lugar que costuma ocupar no mundo das relações humanas que a circunda não corresponde mais às suas potencialidades e se esforça para modificá-lo (LEONTIEV, 1998). O que desencadeia a viragem é a percepção de que existe uma contradição entre o modo de vida da criança e suas potencialidades, que, em tese, nesse momento já o superaram.

Enfim, a compreensão de uma determinada idade exige que se leve em conta a neoformação característica da mesma e a dinâmica da passagem de uma idade a outra. Dito de outro modo, as mudanças na atividade dominante e o jogo de alternância entre idades estáveis e momentos de crise. Então, o modo como Vygotski teoriza sobre o problema da periodização do desenvolvimento psicológico exige, sobretudo, que consideremos um ponto: tendo em vista que o conteúdo de cada estágio subordina-se aos modos de relação social, que são mutáveis, os momentos de início e término dos estágios são variáveis, inclusive dentre as pessoas de um mesmo grupo etário. Isto é, embora os estágios sejam mais ou menos semelhantes em diferentes pessoas, não há nenhuma possibilidade de um esquema universal que represente a dinâmica entre o interno e o externo no processo de aprendizagem e desenvolvimento.

E assim, se considerarmos ainda a concepção vygotskiana acerca das relações temporais entre aprendizagem e desenvolvimento (VYGOTSKI, 1989a, 1989b, 2001), haveremos de concordar, também, que não existe nenhuma garantia de que o processo de aprendizagem 
de uma criança seja igual ao de outra, nem no tempo, nem no lugar (TEIXEIRA, 2005).

\section{Possíveis critérios para a periodização dos ciclos de aprendizagem}

Achamos que cabe uma indagação neste momento: se considerarmos adequadas as teses da teoria histórico-cultural para a periodização do desenvolvimento psicológico, que critério podemos estabelecer como básico para a delimitação dos ciclos de aprendizagem? Ou ainda, para fundamentar sua implantação com base na psicologia vygotskiana? Uma possível resposta para essas indagações poderia ser algo como: o critério básico é a situação social de desenvolvimento em que as crianças se encontram.

Tomamos como pressuposto que Davidov tem razão em considerar que o conceito de situação social de desenvolvimento (de Vygotski) tem muita semelhança, senão total coincidência, com o conceito de atividade dominante (de Leontiev). Entendemos que esse conceito implica uma referência direta ao fato de que os modos de relação interpessoal estão marcados pelas posições que as pessoas ocupam no contexto relacional, em termos de uma certa "maturidade". Por exemplo, um adulto não se relaciona com uma criança de três anos da mesma forma que se relaciona com outro adulto; nem da mesma forma que se relaciona com um adolescente; ou, ainda, nem da mesma forma que se relaciona com outra criança de maior idade. Mas, por outro lado, convém notar que as formas de relacionamento interpessoal entre pessoas de igual ou de diferente situação social de desenvolvimento, também são marcadas socialmente.

O desenvolvimento da psiqué de uma criança é determinado diretamente pelos processos reais da sua própria vida. Por essa razão, opina Leontiev (1998, p. 63), "a mudança do lugar ocupado pela criança no sistema das relações sociais é a primeira coisa que precisa ser notada quando se tenta encontrar uma resposta ao problema das forças condutoras do desenvolvimento". Assim sendo, o estudo do desenvolvimento psicológico tem de começar pela análise da atividade da criança e, mais exatamente, como esta atividade - sobretudo a dominante - é constituída nas condições concretas de sua vida. Disso 
decorre que a periodização deve subordinar-se, em última instância, aos modos de relação social constituídos historicamente.

Ora, não nos parece inadequado transferir essas conclusões para o contexto da educação escolar. Até mesmo porque a sequiência e a mudança da situação social de desenvolvimento - que é a base da periodização da teoria histórico-cultural - coincide com a divisão do ensino escolar em suas etapas. Divisão esta que, por sua vez, se orienta pela experiência historicamente acumulada na educação da criança (DAVIDOV, 1988; VIGOTSKI, 1996). As idades (períodos) do desenvolvimento psicológico são mais ou menos correlatas às divisões que têm sido feitas nos graus de ensino.

Portanto, se levarmos em conta o conceito de situação social de desenvolvimento, o fato de que em cada idade predomina um tipo de atividade e que existe uma neoformação psicológica típica; e o fato de que a aprendizagem de conteúdos escolares requer, pelo menos nos momentos iniciais de cada fase da escolarização, um certo nível de maturação de certas funções psicológicas (TEIXEIRA, 2005), podemos dizer que a teoria histórico-cultural orienta na direção de que os ciclos de aprendizagem devam ser periodizados consoante as etapas do desenvolvimento psicológico.

Assim, se temos em mente que dentre essas idades encontram-se a idade escolar e a adolescência e que os projetos de escola ciclada, no Brasil, geralmente cobrem o período do Ensino Fundamental (6/7 a 14 anos), então poderíamos propor que os ciclos desse período seriam dois: o primeiro ciclo corresponderia à idade escolar; o segundo ciclo corresponderia, em parte, à adolescência.

Em rigor, aliás, poderíamos estender esse raciocínio para todo o período do desenvolvimento psicológico e dizer que a cada idade estável corresponderia um ciclo de aprendizagem. Nesse caso os ciclos seriam: o ciclo do primeiro ano; o ciclo da primeira infância; o ciclo da idade pré-escolar; o ciclo da idade escolar; o ciclo da adolescência; os ciclos subseqüentes (embora com a ressalva de que, especificamente em relação à aprendizagem escolar, a partir dessa idade, para a maioria das pessoas pelo menos, as condições para a apropriação e produção do conhecimento em níveis mais elevados já devem estar disponíveis e que se o sujeito se aproveitará dessa condição ou não é uma outra 
questão). Considerando-se essa periodização, então as manifestações típicas das idades críticas seriam os sinais mais evidentes de que um determinado sujeito estaria em vias de mudar de um ciclo a outro.

Ora, mas essa idéia de que um ciclo de aprendizagem comporta um ponto de viragem bem determinado remete a algo que se fecha. Sucede que a natureza dialética do desenvolvimento indica que esse é um processo que não se configura como um conjunto de eventos bem demarcados, claramente localizáveis apenas em determinados momentos do percurso. Assim, embora o surgimento de um novo ciclo de aprendizagem configure uma ruptura, uma negação do ciclo anterior, essa negação nunca é feita de um modo que inviabiliza a incorporação dos avanços do ciclo superado.

Conforme a teoria vygotskiana acerca das relações temporais entre aprendizagem e desenvolvimento, um ciclo de aprendizagem talvez deva iniciar-se numa idade crítica. Ou seja, antecipando-se, em algum sentido, à consolidação da maturação biológica e das funções psicológicas típicas de uma idade estável.

Assim, os critérios de viragem seriam de naturezas distintas: Biológicos, no sentido de que a aprendizagem e o desenvolvimento pressupõem um certo grau anterior de maturação - ainda que seja no ponto de partida e como aspecto secundário - para continuarem avançando; cognitivos, no sentido da intelectualização das funções psicológicas, cujo ápice representa seu uso consciente e intencional; comportamentais, como o demonstram a atividade dominante e as atitudes típicas das idades críticas e das estáveis.

Mas, esses critérios seriam, sobretudo, histórico-culturais, uma vez que a delimitação dos períodos do desenvolvimento depende de condições históricas concretas, o que implica, por sua vez, que o conteúdo mesmo de cada idade seja, de alguma forma, determinado pelas formas de cultura socialmente elaboradas. Deveriam ser culturais, porque o desenvolvimento psicológico só é possível porque o sujeito se apropria do resultado do desenvolvimento das gerações anteriores. 


\section{Considerações finais}

As discussões e tentativas de reorganização da escolarização no Brasil, que culminaram nos atuais projetos pedagógicos de ciclos de aprendizagem, se iniciaram na década de 1920 (BARRETO \& MITRULIS, 1999; JACOMINI, 2002; TEIXEIRA, 2004). Quanto aos argumentos de natureza psicológica que têm sido utilizados em defesa da modalidade de organização da escolarização em ciclos, o mais importante deles, sem dúvida, é o fato de que as pessoas têm ritmos individuais de desenvolvimento e de aprendizagem.

Nesse sentido, ainda na década de 1950, Dante Moreira Leite defendia que era preciso tomar duas medidas básicas para se resolver os problemas causados pelos altos índices de reprovação nas escolas primária e secundária de então: "primeira, a organização de um currículo adequado ao desenvolvimento do aluno; segunda, a instituição da promoção automática" (LEITE, 1999, p. 13). No entender desse autor, tais medidas sustentavam-se nos avanços da psicologia que demonstravam de modo claro os equívocos da concepção de que o aprendizado segue uma linearidade no tempo, consoante a um determinado estágio de maturação. Essa concepção equivocada sustentava (e ainda sustenta), por sua vez, certas periodizações da escolarização, cujo pressuposto parece ser o de que os alunos são capazes de aprender de uma forma mais ou menos uniformizada quanto ao tempo e ao método (TEIXEIRA, 2005).

É fato que o processo letivo tem sua própria lógica de funcionamento, materializada em determinadas formas de organização das atividades escolares, dos currículos e da ordenação dos conteúdos no tempo e no espaço. Não obstante, essa lógica não coincide, necessariamente, com a lógica interna do processo de desenvolvimento e aprendizagem (VYGOTSKI, 2001). Portanto, do ponto de vista dos fundamentos psicológicos da educação, faz todo o sentido buscar formas de se organizar o ensino de modo que se leve em conta, ao mesmo tempo, as especificidades do processo de desenvolvimento psicológico em suas diferentes etapas e as especificidades da educação escolar.

Não obstante, gostaríamos de concluir dizendo que não podemos nos esquecer, todavia, que qualquer periodização do desenvolvimento 
psicológico é apenas aproximada. Isso, a despeito de que a infância geralmente tenha, na teoria histórico-cultural e noutras também, seus períodos mais ou menos definidos de acordo com os períodos da escolarização. Além disso, na medida em que a idade cronológica avança, as periodizações vão ficando mais grosseiras. Por essa razão, o que sugerimos neste texto acerca de possíveis critérios para a periodização de ciclos de aprendizagem, bem como a própria periodização sugerida, devem ser encarados apenas como temáticas para pesquisas mais aprofundadas.

\section{Notas}

* Dr. em Psicologia da Educação. Professor de Psicologia na Universidade Tecnológica Federal do Paraná / Campus Pato Branco. Via do Conhecimento, Km 1 - CEP 85.503 390. Pato Branco, PR. Fone: (46) 3225 - 2541. Fax (46) 3225-2500. E-mail. edival@utfpr.edu.br

\section{Referências}

BARRETO, E. S. \& MITRULIS, E. Os ciclos escolares: elementos de uma trajetória. Cadernos de Pesquisa, São Paulo, (108), 27-48, 1999.

BARRETO, E. S. \& SOUZA, S. Z. Estudos sobre os ciclos e progressão no Brasil: uma revisão. Educação e Pesquisa, São Pulo, 30 (1), 31-50, 2004.

DAVIDOV, V. La enseñanza escolar y el desarrollo psiquico: investigación psicológica teórica y experimental. Moscou: Editorial Progresso, 1988. ELKONIN, D. B. Epílogo. Em VYGOSTKI, L. S. Obras Escogidas, (Tomo IV, pp 387-412). Madrid: Visor/MEC, 1996.

FREITAS, L. C. Ciclos, seriação e avaliação: confronto de lógicas. São Paulo: Moderna, 2003.

JACOMINI, M. A. A escola e os educadores em tempos de ciclos e progressão continuada: uma análise das experiências no estado de São Paulo. Educação e Pesquisa, São Paulo, 30 (3), 401-418, 2004.

LEITE, D. M. Promoção automática e adequação do currículo ao desenvolvimento do aluno. Estudos em Avaliação Educacional, São Paulo, (19), 5-25, 1999. 
LEONTIEV, A. N. O desenvolvimento do psiquismo. São Paulo: Moraes, 1983.

LEONTIEV, A. N. Uma contribuição à teoria do desenvolvimento da psique infantil. Em VIGOTSKII, L. S.; LURIA, A. R. e LEONTIEV, A. N. Linguagem, desenvolvimento e aprendizagem. 6. ed. São Paulo: Ícone, 1998, p. 59-83.

MAINARDES, J. Organização da escolaridade em ciclos no Brasil: revisão da literatura e perspectivas para a pesquisa. Educação e Pesquisa, São Pulo, 31 (1), 2006.

OLIVEIRA, M. K. e TEIXEIRA, E. A questão da periodização do desenvolvimento psicológico. Em OLIVEIRA, M.K.; SOUZA, D. T. R. \& REGO, T. C. (Orgs.). Psicologia, educação e as temáticas da vida contemporânea. São Paulo: Moderna, 2002.

PARO, V. H. Reprovação Escolar: renúncia à educação. São Paulo: Xamã, 2001.

TEIXEIRA, E. S. A questão da periodização do desenvolvimento psicológico em Wallon e em Vigotski: alguns aspectos de duas teorias. Educação e Pesquisa,São Paulo, 29 (2), 2003.

TEIXEIRA, E. S. Relações temporais entre aprendizagem e desenvolvimento e periodização da escolarização: uma reflexão na perspectiva vigotskiana. Educar em Revista, Curitiba, (26), 215-231, 2005.

VASCONCELLOS, C. S. Ciclos de formação: um horizonte libertador para a escola no $3^{\circ}$ milênio. Revista de Educação AEC, Brasília, (111), 830-895, 1999.

VIGOTSKI, L. S. A construção do pensamento e da linguagem. São Paulo: Martins Fontes, 2001.

VYGOSTKI, L. S. Obras Escogidas, (Tomo III). Madrid: Visor/MEC, 1995.

VYGOSTKI, L. S. Obras Escogidas, (Tomo IV). Madrid: Visor/MEC, 1996.

VYGOTSKY, L. S. A formação social da mente. 3ed. São Paulo: Martins Fontes, 1989a.

VYGOTSKY, L. S. Pensamento e Linguagem. São Paulo: Martins Fontes, 1989b. 


\section{Abstract: \\ THE BORDER LINE OF LEARNING CICLES AND THE PSYCHOLOGICAL DEVELOPMENT PERIOD SYSTEMATIZATION}

The objective of this work is to contribute for the discussion on the question of the schooling organization in learning cycles. In the text it is affirmed that there are gaps in the research on this modality of pedagogical organization, over all, in relation to its psychological basis. The problem of the inferior and superior thresholds delimitation of the cycles is distinguished, and it is argued that it is exactly in this aspect that the most difficult question for the psychological research in this area is found. The text presents some aspects of Vygotski's theory on psychological development and, with the basis of the concept of the social situation development and in the periodization elaborated by Vygotski, it suggests a periodization of learning cycles. Notwithstanding, the work concludes affirming that such suggestion only must be faced as a provocation in the sense of promoting the raising of themes for the research on psychological basis for pedagogical projects of learning cycles.

Keywords: learning cycles; psycological development; Vygotsky.

Recebido em 09 de abril de 2008.

Aceito em 11 de maio de 2008. 